\title{
The Enlightenment of Deepening the Reform Theory on College Students' Learning
}

\author{
Xin Chen $^{1}$ and Xiaoyan $\mathrm{Li}^{2}$
}

${ }^{1}$ College of Science and Technology, Jingdezhen Ceramic University, Jindezhen, Jiangxi 333000;

${ }^{2}$ Jingdezhen Ceramic University, Jingdezhen, Jiangxi 333403

\begin{abstract}
At the national level, profound reforms at all levels have been carried out in accordance with the important theory of deepening the reform, and the reform of China has been systematically progressively. Each major reform will determine the fate of China. From the individual level of contemporary college students, to achieve the self-worth of college students, we should learn from the country's reform system, the corresponding self-development of the systematic reform, that is, professional learning outside the study to enrich the university life, improve the comprehensive quality. Based on the deepening of the scientific connotation of the reform, this paper analyzes the problems existing in the study of contemporary college students and clarifies the guiding significance of the reform thinking to the development of the foreign students. Finally, it discusses the revelation of the reform of the contemporary college students from the deepening of the reform theory.
\end{abstract}

Keywords: Comprehensively deepening reform; College students; Learning; Enlightenment

\section{全面深化改革理论对大学生学习的启示}

\author{
陈欣 ${ }^{1}$ 李晓燕 $^{2}$
}

( 景德镇陶瓷大学科技艺术学院, 江西 景德镇 333000; 景德镇陶瓷大学, 江西 景德镇 333403 )

摘要: 在国家层面, 已经在按照全面深化改革的重要理论进行各个层面的深刻改革, 系统化地逐步推进中国 的改革, 回顾历史, 展望未来, 每次重大改革都将决定中国的命运。那么, 从当代大学生的个体层面来说, 要实 现大学生的自我价值, 也应该借鉴国家的改革体系, 相应的对自我发展进行系统化的改革, 即进行专业本身学习 以外的学习, 以丰富大学生活, 提高综合素质。本文从全面深化改革的科学内涵出发, 分析当代大学生在学习中 存在的问题, 并明确全面深化改革思维对开展专业外学习的指导意义, 最后从全面深化改革理论对当代大学生学 习的启示进行了论述。

关键词: 全面深化改革; 大学生; 学习; 启示

中图分类号: G40-058 文摘标识码: A

\section{1 全面深化改革理论的科学价值}

\section{1 诠释了国家的发展方向}

马克思主义之所以在全世界得到了广泛共鸣与发展, 是因为她揭示了社会发展的规律, 为无 产阶级的革命斗争指明了方向。全面深化改革理论, 深层次地从掌握国家政治、经济等各个领域 的发展规律出发, 为开拓中国特色社会主义事业, 为国家的发展指明了方向。 


\section{2 诠释了思想认识与改革实践的统一性}

辩证唯物主义的巨大成就在于强调认识对于实践的依赖关系的同时，也指出在实践基础上产 生的认识对于实践活动具有能动的反作用, 正确的认识对于实践有重要的指导意义。全面深化改 革理论紧密结合中国实际, 高度概括了当今中国面临的若干重大问题, 在此基础上做出了重大决 定，提出了改革方向，并逐步在各个领域实施并全面深化改革，知行合一，体现了认识与实践的 高度统一性。

\section{3 诠释了改革目标与策略的务实性}

“求真务实” 是中国共产党的执政之基，大胆地对中国的改革不断进行解放思想、实事求是、 与时俱进, 深化与精准改革的目标定位, 引领各个领域从策略上认识事务的规律性, 去实践, 让 改革的目标和过程充分具备中国特色的高度可操作性。

\section{2 深化改革理论视角下大学生学习中存在的问题}

\section{1 自我改革不深入:专业学习的局限性}

大学生毕业后所从事岗位的不可预见及岗位对其的要求是大学专业课程学习的最大局限性。 当代大学生大学四年在校期间的课程门数大概在 85 130 之间, 课程模块是由英语、政治、计算 机、军事理论等通识课程、部分学科基础课程、专业核心及专业方向课程所组成, 课程设置虽然 经高校论证, 自成体系, 但是, 对于学生来说, 如果不明确每门课程在专业学习中的地位和重要 性, 不把握如何学习, 等其毕业的时候就真成 “大学就是大概学学” 的状态了, 从每年的高校毕 业生就业来说, 毕业后所从事的岗位, 大部分学生所从事的是和本专业不对口岗位, 而且岗位和 专业学习的不一致性就出现了, 如针对岗位所需要的知识、业务水平甚至是岗位素养, 都大大超 过了大学专业课程学习的全部。如果同学们在校期间不进行拓展性的学习, 不对自身需求做评估, 不对自身的学习进行改革和探索的话, 工作后, 需要半年到 1 年的工作适应期才能逐渐具备岗位 的要求。

\section{2 自我改革认识不到位:对专业外学习思想认识的局限性}

对大学学习定位和方向的不准确是大学生对自身学习改革局限性的首要原因, 很多同学到了 大学开始不知道学什么, 为什么而学习, 导致没有进行拓展性的学习。这也是为什么会出现大学 生在校期间频繁逃课、上课睡觉、玩手机、下课到宿舍玩游戏, 甚至通宵玩游戏, 应付作业、考 前临时抱佛脚等一系列与正能量相反的学习状态出现的原因。

如果同学们能够认识到社会岗位对自身综合素质的需求，能够明白自身在大学学习过程中存 在的知识、能力和素养不足的话, 就需要如同运用全面深化改革治理国家一样, 要根据自身实际 进行系统地围绕 “学习” 而进行改革, 不断的开展拓展性学习, 以提高自身综合素质和社会就业 能力。 


\section{3 自我改革实践未系统化:对专业外学习实践的局限性}

大学生对拓展性学习实践活动未统一到一个系统性层面的高度是个重大局限, 只是在专业课 程理论学习、实践学习之外, 把偶尔参加活动、大赛、体育运动当成是提升综合素质的唯一途径, 未将自身发展如同全面深化改革理论一样, 站在发展方向角度, 将自我学习形成系统化、步骤化、 条理化, 只是将偶然的学习当初是当兵作战, 如果大学生能结合自身实际、社会及其岗位需求对 自身知识、能力与素养的综合要求, 来制定系统性的学习实践规划, 就能将自我发展如同全面深 化改革一样逐步推进, 逐步完善大学生自身建设。

\section{3 全面深化改革对大学生专业外学习的指导意义}

\section{1 改革的全面性符合大学生综合素质提高的要求}

全面深化改革体现的重大特征之一就是改革的全面性, 而对于大学生来说, 综合素质的提高 也是对大学生所面临全面性挑战, 因此二者有方向上的一致性。全面深化改革体现的是国家层面 各个政治、经济、文化、科技、教育等领域破除弊端的深层次改革，大学生综合素质体现的是当 代大学生对自我知识、才能和素养方面的不断完善与提高的过程。

\section{2 全面改革的思想认识符合大学生世界观重塑的要求}

全面深化改革，站在时代高度，站在国家的层面深刻回答了为什么要全面深化改革、怎样全 面深化改革等重大理论和现实问题, 特别是对改革进行了多角度全方位的理论思考, 所体现的高 度的政治性与方向性。这给当代大学生具有高度的指导意义, 尤其是对大学生的学习的指导意义, 即当代大学生要站在大学所学与社会对接的高度, 站在学生个体层面, 多角度多方位的考虑自身 发展问题，树立社会主义正确的世界观和人生观，进行拓展性学习，提高自身能力与素养。

\section{4 全面深化改革理论对大学生专业外学习的启示}

\section{1 有助于对自身发展进行方向规划}

面对错综复杂的国际国内环境，国家正视各类发展中的问题，制定并实施全面深化改革，阐 明了建立更完备、更稳定、更管用的制度体系这一改革新的历史任务和长远战略目标, 满赋正能 量的深遂的历史和战略眼光, 明确了全面深化改革的历史方位, 为国家的发展进行了方向规划。 这给当代大学生的最大启示在于给予思想上的启迪, 发展方向上的启示, 要求当代大学生也能像 国家治理一样, 能正视自己发展中的问题, 并迎难而上, 锐意解决, 号召大家对自身发展进行中 长期的规划, 并付诸实践。

\section{2 有助于坚持学习的目标论}

全面深化改革确定了完善和发展制度、推进治理体系和治理能力现代化为总目标，为深化改 革指引了总的方向, 对于当代大学生来说, 应该借鉴国家的全面改革经验理论, 对在校期间在学 习上的拓展性学习, 确立总目标, 即以自身综合素质的提高为最终目标, 以综合素质的提高为根 
本方向, 以拓展性学习为根本途径。

当代大学生只要坚持拓展性学习的最终目的是为自身综合素质而服务的, 就能牢牢把握住大 学学习的定位和方向, 只要能够在知识、才能和素养的拓展性学习过程中, 逐渐清晰并明白为什 么上大学? 怎样上好大学? 才能逐渐从网络游戏、上课玩手机、逃课等现象中摆脱出来, 逐步在 大学现实生活中, 珍惜奋斗和学习的过程。

\section{3 有助于坚持学习的任务论}

全面深化改革坚持以完善和发展社会主义制度体系为历史任务, 为国家的长治久安提供一套 更完备、更稳定、更管用的制度体系。当代大学生要继承和发展这一任务理论, 为自我的长远发 展制定一套知识、才能和素养的以提高综合素质的具体学习任务, 例如, 针对知识的学习, 除了 学习本专业课程知识体系之外, 还可以根据兴趣爱好拓展性地开展相关知识的学习, 甚至是网络 游戏, 也可以课外去研究自己喜欢的游戏的软件开发、游戏场景及人物形象设计、游戏市场等等, 这样还能避免只是盲目地、低趣味的追逐网络游戏的娱乐性, 因为对于网络游戏来说, 也是一个 巨大的产业链。

\section{4 有助于坚持学习的方法论}

习近平同志指出: “改革开放是前无古人的崭新事业, 必须坚持正确的方法论, 在不断实践 探索中前进”、“必须从纷繁复杂的事物表象中把准改革脉搏, 把握全面深化改革的内在规律”。 共产主义革命之所以能在俄国、中国成功，是因为二国在国情的基础上坚持了正确的方法论，一 定要把握事物的内在规律, 改革才能成功。比如大学生针对自我综合素质中的体育锻炼来说, 运 动项目、运动时间与时限、动作强度都是方法的关键, 因此拓展性学习, 一定要通过各种途径掌 握方法和技巧，而不是一味的打时间的持久战，而是要追求高效率。

\section{5 有助于坚持学习的定力论}

当代大学生的拓展性学习, 要有方向、有立场、有原则, 保持战略定力, 保持学习的正能量 的坚定性，要保持是自我完善与发展道路上的前进的学习改革，不走改旗易帜的邪路，端正在大 学的学习态度, 对利益、经济、社会地位的追逐保持在正道。例如能正确的学习营销、实践营销, 认识营销, 以防止落入非法传销组织的陷阱等。

\section{6 有助于坚持学习的时态论}

当代大学生的自我改革, 针对拓展性学习, 是一项长期的、艰巨的、繁重的学习过程, 必须 持续保持下去, 改革没有完成时态, 只有正在进行时态, 坚持拓展性学习的过程论, 要正确对待 成功与失败, 逐渐树立 “总结是成功之母” 的观点, 而不是遇到一点挫折和失败就失去了信心与 自我改革的动力, 也不是当达到一地既定目标就停止不前, 要把拓展性学习当成是自我完善与提 高的过程，继续保持下去。

\section{7 有助于坚持学习的担当论}


当代大学生对于自我完善与提高的拓展性学习, 要保持进取意识和责任意识, 勇于担当自己 所在的角色, 勇于承担, 勇于面对自身发展的束缚和困难, 做好攻坚克难的准备, 才能提升对社 会的奉献能力。作为学生, 就要做一名合格的学生, 甚至是出色的学生; 作为家庭成员, 就要做 一名能为自己所在家庭承担重任, 能为家庭分忧。

\section{致谢}

基金项目：江西省教育厅教学改革研究基金项目（JXJG-15-39-3）

\section{Acknowledgement}

Fund Project: Jiangxi Provincial Department of Education Teaching Reform Research Fund Project (JXJG-15-39-3)

\section{参考文献}

[1] 中共中央关于全面深化改革若干重大问题的决定（全文）

[2] 习近平关于全面深化改革的十大重要论点

[3] 张立平. 拓展性学习中的概念形成一一基于 “文化一历史” 活动理论的视角. 教育学术月刊, 2014（04） 作者简介:

陈欣 (1983-)，男，江西永丰人，景德镇陶瓷大学科技艺术学院讲师，主要研究方向：管理学。

李晓燕 (1980-) , 女, 内蒙古四子王旗人, 景德镇陶瓷大学计划财务处, 中级会计, 主要研究方向: 管理 学。

\section{References}

[1] Decision of the Central Committee of the Communist Party of China on Deepening the Reform of Several Major Issues (Full Text)

[2] Xi Jinping's Ten Important Theories on Deepening the Reform

[3] Zhang Li-ping. The Conceptual Formation in Expanding Learning - From the Perspective of the Theory of "Culture - History". Education Monthly, 2014 (04) 